\title{
Análise Aerodinâmica e Térmica de uma Câmara de Combustão anular de Turbinas a Gás Utilizando CFD
}

\author{
Aerodynamic and Thermal analysis of a Combustion chamber annular of \\ Turbines Gas Using CFD
}

\author{
Lucilene de Oliveira Rodrigues \\ Prof. Dr. Marco Antonio Rosa do Nascimento
}

Artigo

Original

Original

Paper

\section{Resumo}

Dinâmica de Fluido Computacional

Câmara de

Combustão

Aerodinâmica

Temperatura
Para a solução de problemas complexos da engenharia e da física, têm sido utilizadas técnicas numéricas, graças ao grande desenvolvimento de computadores de alta velocidade e capacidade de armazenamento. $O$ engenheiro utiliza três ferramentas para o desenvolvimento de projetos $e$ análise de problemas, são elas: métodos analíticos, numéricos e experimentais. Os métodos analíticos e numéricos formam a classe dos métodos teóricos, pois objetivam resolver as equações diferenciais que formam o modelo matemático, sendo a complexidade das equações, a diferença entre eles. Com relação à experimentação em laboratório, esta tem a vantagem de se tratar com uma configuração real, porém, nem sempre é possível ou viável devido ao altíssimo custo e, algumas vezes, não poder ser realizada por motivos de segurança. Os resultados obtidos com as simulações, são usados para obter importantes informações durante a fase do projeto ou otimização de equipamentos industriais. Sua utilização gera resultados de confiança a um baixo custo, devido ao número reduzido das experiências, como também a oportunidade de desenvolver novos produtos e de executar muitas simulações antes de sua produção. Este trabalho visa apresentar resultados da aerodinâmica de câmaras de combustão, como também a análise temperatura, utilizando uma ferramenta de CFD (Dinâmica Fluida Computacional), através do software CFX.

\section{Abstract}

The use of numerical techniques for the solution of complex problems of engineering and the physics has been used thanks to the great development of computers of high speed and capacity of storage. The engineer uses three tools for the development of projects and analysis of problems, they are: analytical, numerical and experimental methods. The analytical and numerical methods form the classroom of the theoretical methods, therefore they objectify to decide the distinguishing equations that form the mathematical model, being the complexity of the equations, the difference between them. With regard to the experimentation in laboratory, this has the advantage of if dealing with a real configuration, however nor always possible or viable it must to the highest cost and some times power not be carried through by security reason. The results gotten with the simulations, are used to get important information during the phase of the project or optimization of industrial equipment. Its use generates resulted reliable to a low cost, which had to the reduced number of the experiences, as well as the chance to develop new products and to execute many simulations before its production. This work aims at to present resulted of the aerodynamics of combustion chambers, as well as the analysis temperature, using a CFD tool (Computation Fluid Dynamics), through software CFX.
Key words:

Computation Fluid

Dynamics

Combustion chamber

aerodynamic

temperature 
Uma técnica de análise que vem

As microturbinas têm sido alvo de pesquisas desde 1970 pela indústria automobilística e seu uso tem se intensificado à medida que se tem maior conhecimento sobre o assunto. As microturbinas a gás apresentam boas perspectivas para geração distribuída de eletricidade de pequeno porte, pois, apresentam características como: alta confiabilidade, simplicidade de projeto, compacta, de fácil instalação e manutenção.

A participação das unidades de geração termelétrica com turbina a gás no setor elétrico brasileiro já constitui mais de 21 [\%] dos empreendimentos de geração elétrica em operação, de acordo com dados fornecidos pelo Ministério de Minas e Energia (2006), totalizando uma potência de aproximadamente 41 [GW] em relação ao total instalado de 195 [GW].

Devido aos fatos citados, o estudo das microturbinas a gás se torna interessante e importante ao desenvolvimento tecnológico e, em particular, o estudo das suas câmaras de combustão. Como a câmara de combustão é responsável por queimar o combustível e liberar energia (calor), dando origem a uma corrente suave e uniforme de gases, que serão expandidos na turbina, este componente está diretamente relacionado com a eficiência e com a emissão de poluentes, fatores de extrema importância para o desenvolvimento de novos projetos ou aprimoramento de equipamentos existentes.

A atratividade das turbinas a gás de menores potências é baseada, principalmente, nas possibilidades de conseguir níveis de desempenho satisfatório sem um aumento dramático nos valores da relação de pressão do ciclo e das temperaturas da entrada da turbina, evitando assim, o aumento dos custos de manufatura de componentes, como também, diminui a necessidade da utilização de ligas metálicas mais nobres. O estudo de câmaras de combustão é muito complexo devido ao grande número de variáveis envolvidas, principalmente, no que diz respeito às reações do processo de combustão. Devido à sua complexidade, a análise desse componente se torna onerosa no processo de desenvolvimento, sendo necessária a utilização de simulações numéricas, para que este estudo seja viável, eficiente e com menor custo. sendo largamente utilizada em diversas áreas, inclusive em estudos de câmaras de combustão, é a Dinâmica de Fluidos Computacional (CFD), capaz de melhorar produtos que já estão no mercado, como também idealizar novos produtos, mais eficientes e com um número reduzido de testes experimentais. Essa metodologia geralmente é baseada nos métodos numéricos do tipo diferenças finitas, elementos finitos e volumes finitos. Para se conseguir bons resultados, utilizando a Dinâmica de Fluido Computacional, deve-se ter equipamentos adequados e robustos, além de pessoal capacitado e comprometido com as simulações.

À medida que as pesquisas evoluem, modelos matemáticos mais robustos e computadores mais rápidos são desenvolvidos, permitindo projetar câmaras de combustão mais eficientes, com baixas emissões de poluentes e a um baixo custo. Por esse caminho é possível melhorar os processos e desenvolver novas tecnologias para as câmaras de combustão.

\section{REVISÃO BIBLIOGRÁFICA}

\section{Micro turbinas a Gás}

A primeira tentativa bem sucedida a produzir trabalho com turbina a gás foi alcançada por Aegidius Elling, em 1903, na qual a turbina a gás projetada produziu um trabalho de eixo de 11 hp, com uma câmara de combustão a pressão constante. Em se tratando de turbina a gás com volume constante, esta foi construída entre 1908 e 1913, proposta por Hans Holzawawrth.

Em se tratando de ciclos simples, as turbinas a gás podem assumir algumas configurações, que podem ser vistas na Figura 1. Visando solucionar problemas aerodinâmicos de compressão e desempenho de operação, baseados na aplicação específica, o ciclo simples pode apresentar configurações diferentes e as turbinas podem, assim, ser divididas em dois grupos, sem turbina livre e com turbina livre. Em configurações com turbina livre ou de potência e gerador de gás, (onde o gerador de gás pode ser de um, dois ou três eixos), os casos com mais de um eixo, têm a finalidade de aumentar a eficiência térmica, aumentando a razão de pressão do ciclo, com isso, divide-se a compressão em vários estágios, aumentando a eficiência 
aerodinâmica do processo de combustão. Outras possíveis configurações de turbinas a gás são: adição de resfriamento intermediário (intercoolers) entre os compressores, câmaras adicionais de combustão, trocadores de calor, com injeção de vapor e água. Todas as variações citadas visam aumentar a potência útil e a eficiência térmica, porém, aumentando não somente a complexidade dos equipamentos, como também o seu peso e os custos. Maiores detalhes sobre aos ciclos de produção de energia com turbinas a gás podem ser encontrado em Lora e Nascimento (2004).

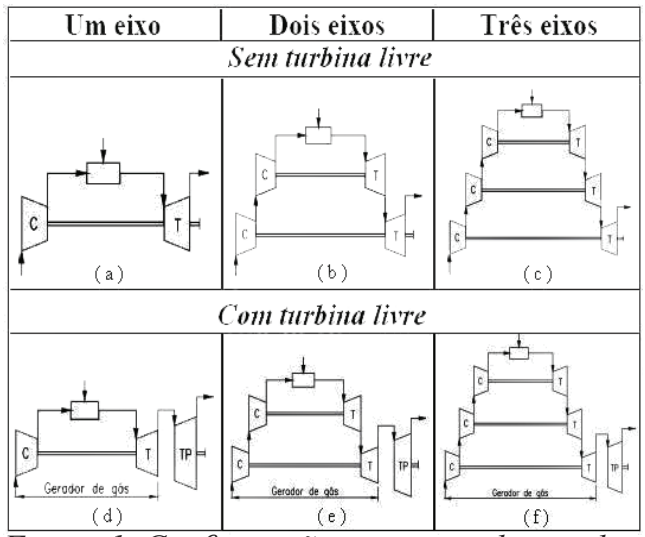

Figura 1. Configurações para o ciclo simples.

As turbinas a gás regenerativas usam os gases de exaustão, no trocador de calor (regenerador), para aquecer o ar que sai do compressor, antes da sua entrada na câmara de combustão. Com o pré-aquecimento do ar, o consumo de combustível é reduzido, aumentando a eficiência térmica do ciclo. Este ciclo é representado na Figura 2a. Com o objetivo de aumentar ainda mais a eficiência térmica e o trabalho útil do ciclo, pode-se adicionar simultaneamente ao ciclo, além do trocador de calor regenerativo, um intercooler, cuja função é reduzir o trabalho de compressão, aumentando o trabalho útil do ciclo. Na Figura 2b, é mostrada essa configuração, onde a compressão ocorre em dois compressores, tendo um interccoler entre eles para reduzir a temperatura do ar que entra no segundo compressor. O trabalho específico é aumentado, pois o trabalho de compressão é função da temperatura de entrada do ar, ou seja, uma redução na temperatura de entrada causa redução no trabalho de compressão.

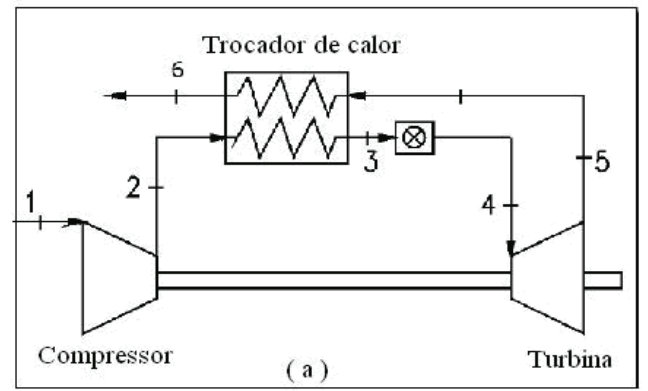

Figura 2 - A. Ciclo regenerativo ideal

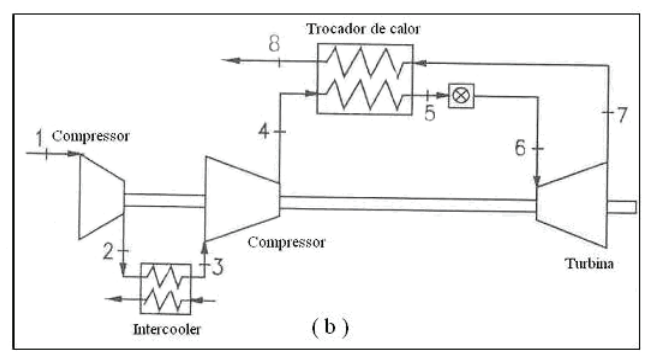

Figura 2 - B. Ciclo regenerativo com intercooler

Emturbinasagásqueutilizamainjeção de vapor, Figura 3a, este é injetado na saída do compressor, aumentando o trabalho produzido, já que aumenta a vazão em massa que expande na turbina. Esse vapor pode ser gerado numa caldeira de recuperação com aproveitamento da energia dos gases de exaustão da turbina. Outra vantagem importante da injeção de vapor é a redução das emissões de NOx, item significativo em projetos. Essa redução é devida à criação de uma mistura uniforme de vapor e ar, ou seja, reduzindo a temperatura na zona de combustão e, consequentemente, diminuindo a formação de NOx. $\mathrm{O}$ ciclo com injeção de água, Figura 3b, apresenta as vantagens do ciclo regenerativo, somadas àquelas do ciclo com injeção de vapor, entre elas: redução de emissão de NOx e alta eficiência térmica. Um atomizador de água é colocado entre o compressor e a câmara de combustão. A queda de temperatura do ar pela adição de água é recuperada no regenerador, próximo componente do sistema. Porém, essa configuração tem alguns problemas, os quais são: a corrosão do regenerador devido a presença de água, a possibilidade de o regenerador incendiarse, pois este tende a desenvolver pontos quentes quando não está totalmente limpo.

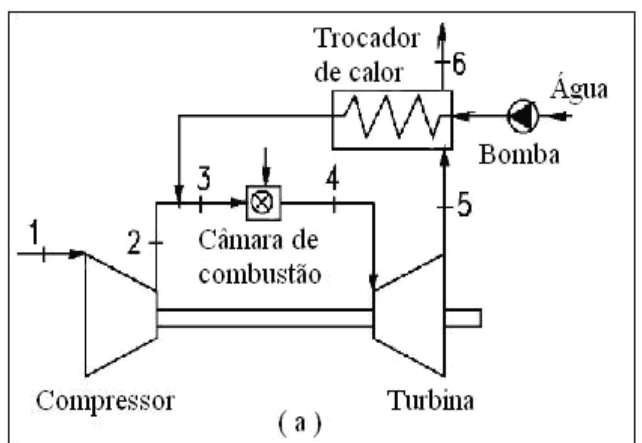

Figura 3 - A. Ciclo com injeção de vapor

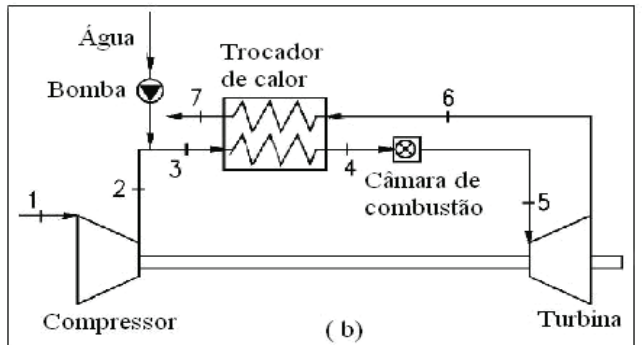

Figura 3 - A. Ciclo com injeção de vapor 
As câmaras de combustão de turbinas a gás têm a finalidade de queimar uma quantidade de combustível fornecida pelo injetor, com uma grande quantidade de ar, proveniente do compressor, e liberar o calor de tal maneira que o ar seja expandido e acelerado, de forma a resultar numa corrente suave e uniforme do gás quente, a qual é necessária à produção de potência pela turbina. Isso deve ser alcançado com a mínima perda de pressão e a máxima eficiência. Um esquema de um ciclo simples pode ser visto na Figura 4.

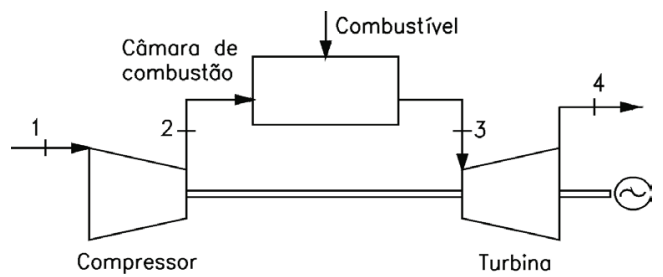

Figura 4 - Ciclo simples

Em microturbinas que possuem um único eixo, neste estão montados o compressor, a turbina e o gerador. Como esse conjunto trabalha a alta rotação, há muitas perdas por atrito, por isso, havendo maior necessidade de resfriamento, principalmente, se o gerador se encontra próximo das partes quentes da microturbina. Em algumas configurações, para promover o resfriamento do gerador, este é colocado no duto de admissão de ar, produzindo uma queda de pressão estática na entrada do compressor e um aumento da temperatura do ar, Figura 5.

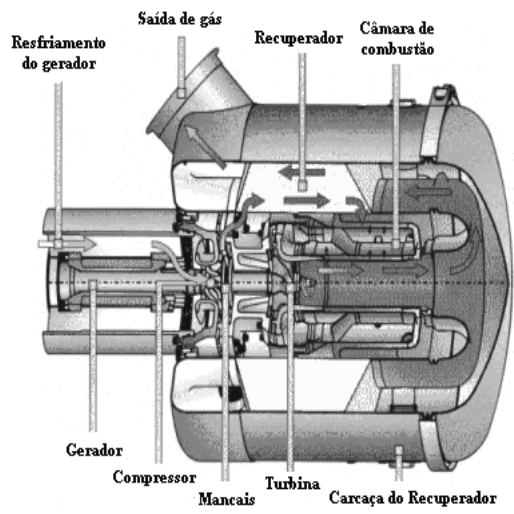

Figura 5 - Exemplo de Microturbina (Capstone Co.)

Hoje em dia, para se projetar uma câmara de combustão, pode-se contar com ajuda de softwares de simulação numérica, que contribuem para um projeto de boa qualidade, com resultados satisfatórios e a um baixo custo. Diferentes métodos podem ser utilizados para a análise de câmaras de combustão. Dentre eles, o CFD (Computational Fluid Dynamics), baseado no Método de Volumes Finitos, tem sido largamente utilizado para análise de câmaras de combustão anulares e tubulares. Por exemplo, Lai (1997), utilizou as análises CFD, para uma previsão exata dos pontos quentes, que correspondem às localizações dos pontos mais críticos para o combustor, Turrel et al (2004) verificaram os picos de temperaturas na NGV central, Darbyshire et al (2006), estudaram as condições de entrada da mistura combustível e ar, entre outros.

À medida que as pesquisas evoluem, modelos matemáticos mais robustos $\mathrm{e}$ computadores mais rápidos são desenvolvidos, permitindo projetar câmaras de combustão mais eficientes, com baixas emissões de poluentes e a um menor custo. Por esse caminho, é possível melhorar a modelagem da combustão, Kuo(1986), alcançando resultados mais precisos, em menor tempo e a um custo reduzido.

Para aumentar a temperatura do fluxo de ar, a câmara de combustão deve satisfazer vários requisitos, entre eles:

- Deve ser capaz de garantir a ignição em várias condições;

- Operar de forma estável em várias condições;

- Promover a queima completa minimizando a formação e emissão de poluentes;

- Promover a mistura e diluição dos gases de queima para evitar danos na turbina devido ao gradiente de temperatura dos gases de exaustão;

- Obter um perfil de temperatura uniforme na saída da câmara de combustão;

- Ter baixa perda de carga;

- Ter o tamanho, peso e custo reduzidos, além de vida útil aceitável.

\section{Métodos numéricos aplicados a combustores}

Vários estudos têm sido realizados sobre câmaras de combustão, devido à necessidade contínua dos avanços das tecnologias das turbinas a gás. Com a introdução de novos conceitos de combustores, que apresentam valores muito baixos de emissões, juntamente com desenvolvimento simultâneo na preparação de combustíveis e técnicas de resfriamento das paredes do tubo de chama, um estudo mais detalhado deste importante componente das turbinas, se faz necessário.

Lefebvre, em 1998, apresentou um estudo de vários aspectos da combustão de turbinas a gás, entre eles conceitos básicos sobre os tipos de combustores, fundamentos da combustão, difusores, aerodinâmica, desempenho da combustão, injetores de combustíveis, formação de ruídos e transferência de calor. 
A adição de hidrogênio à reação de combustão foi estudada por alguns pesquisadores, devido a sua significativa mudança no comportamento da chama. Em 2002, Tomczak et al estudaram uma câmara de combustão tubular, utilizando diferentes concentrações de metano e hidrogênio. Podese concluir com esses estudos que houve redução do alcance da chama, aumento da temperatura da chama e, por consequência, aumento de emissões de NOx e CO. Esse fato também foi verificado por Cozzi e Coghe (2006), porém, utilizando gás natural como combustível, variando as concentrações de hidrogênio. Já Ilbas et al (2006), fizeram a análise das misturas ar-hidrogênio e arhidrogênio-metano, e concluíram que diminuindo o percentual de hidrogênio nas misturas ar-hidrogênio-metano, pode ocorrer um aumento da velocidade da chama.

Segundo estudos realizados por Sadiki et al (2004), quando a intensidade da turbulência aumenta, a eficiência da transferência de massa também é aumentada. O aumento do grau do swirl acentua a taxa de mistura e exerce forte influência no processo de combustão.

De acordo com circunstâncias operacionais, uma configuração apropriada para o combustor deve superar alguns problemas, tais como: os limites de flamabilidade e atraso na ignição para o início e desenvolvimento da combustão, o excesso em frações de hidrocarbonetos não queimados ou índices de $\mathrm{CO}$ e as não uniformidades na distribuição da temperatura na entrada das palhetas da turbina, causadas pelas taxas de reações reduzidas.

O combustor utilizado para os experimentos de Turrell et al (2004) foi o combustor DLE (combustor com pré-mistura pobre de baixas emissões) industrial da Demag Delaval Turbomachinery, onde foi realizada a validação da análise CFD aplicado à relação de combustor/turbina.

Foi utilizado o modelo de turbulência k- $\varepsilon$ e o modelo das tensões de Reynolds (RSM), para a verificação da resolução de ambos. Na Figura 6, em que é mostrado a magnitude da velocidade tangencial, pode se verificar que o modelo das tensões de Reynolds (RSM) apresenta uma solução melhor do que o modelo $\mathrm{k}-\varepsilon$, ou seja, os resultados obtidos são mais refinados, podendo ser identificados mais detalhadamente as variações, tanto de velocidade, como também de pressão e temperatura do objeto de estudo. Uma desvantagem desse modelo é a alta complexidade de suas equações.

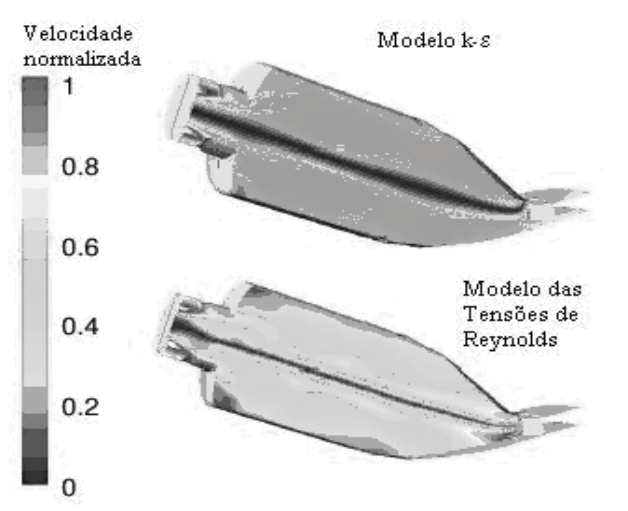

Figura 6 - Velocidade tangencial normalizada no plano diametral através do combustor. Comparação entre o modelo k-e e modelo das tensões de Reynolds.

\section{DESCRIÇÃO DA CÂMARA DE COMBUSTÃO DA SOLAR TURBINES}

A câmara de combustão estudada neste trabalho pertence a uma microturbina a gás do tipo anular, fabricada pela Solar Turbines Modelo T-62T-32 com potência de 60 [kW]. Essa microturbina é muito compacta e relativamente leve, pesando em torno de 68 $\mathrm{kg}$. Algumas partes dessa microturbina, onde se encontra a câmara de combustão, podem ser vistas na Figura 7.
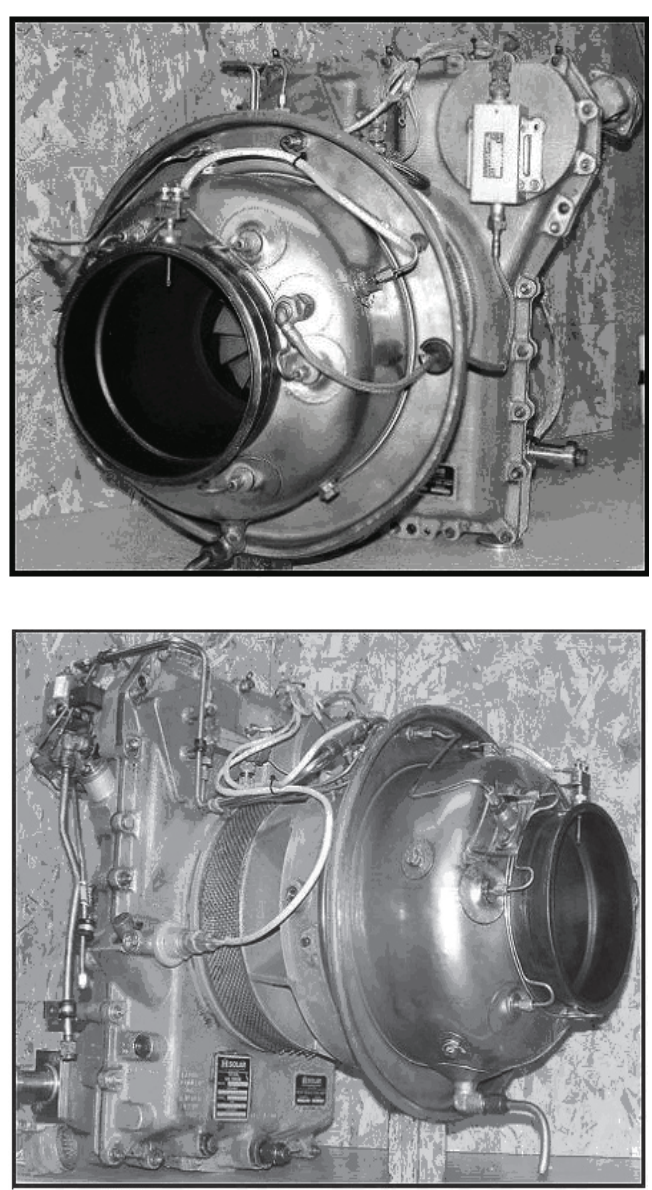

Figura 7 A/B. Microturbina, modelo T-62T-32 fabricada pela Solar Turbines. 
Algumas características operacionais e de manutenção desta microturbina podem ser encontradas no Technical Manual Overhaul (1992), de onde foram extraídos os dados técnicos necessários para as simulações.

A câmara de combustão da microturbina citada e que foi simulada neste trabalho, apresenta 6 bicos injetores, cujos ângulos de inclinação são de $60^{\circ}$ em relação a direção axial. Contém também 86 orifícios primários, presentes na zona de combustão, somados a 46 orifícios secundários, ou de diluição. Esses orifícios são utilizados para se obter uma melhor distribuição do fluxo no interior da câmara, ancoragem da chama, formação de um filme de resfriamento próximo ao tubo de chama, além de servirem para diluir os gases produtos da combustão, favorecendo a dissociação dos poluentes formados na região da chama.

A microturbina fabricada pela Solar Turbines se encontra instalada no Laboratório de Microturbinas e Gaseificação de Biomassa da Universidade Federal de Itajubá.

O combustível utilizado foi o gás natural e a câmara simulada, fabricada pela Solar Turbines, foi projetada para combustíveis líquidos (querosene). O poder calorífico destes combustíveis tem valores próximos, sendo que o PCI do gás natural é $47 \mathrm{MJ} / \mathrm{kg}$ e do querosene é $43 \mathrm{MJ} / \mathrm{kg}$. Algumas diferenças serão notadas quando analisada a combustão, como por exemplo, na quantidade de ar necessária para a zona primária da combustão e para a diluição, como também no tempo de residência, que no caso dos líquidos é maior.

\section{MODELAGEM DA CÂMARA DE COMBUSTÃO DA SOLAR TURBINES}

A composição do gás natural estudado pode ser vista na tabela 1 , onde são mostradas as composições em frações molares e mássicas de cada componente. Para a análise do processo de combustão, utilizou-se, inicialmente, o Software Gaseq, para a estimativa da temperatura adiabática da chama que, para este caso, foi de 2180 [K] aproximadamente.

Tabela 1. Composição do gás natural utilizado

\begin{tabular}{|c|c|c|}
\hline \multirow{2}{*}{ Espécies } & \multicolumn{2}{|c|}{ Composição } \\
\cline { 2 - 3 } & Fração molar & Fração mássica \\
\hline $\mathrm{CH}_{4}$ & 0,8795 & 0,7939 \\
\hline $\mathrm{C}_{2} \mathrm{H}_{4}$ & 0,0913 & 0,1128 \\
\hline $\mathrm{CO}_{2}$ & 0,0174 & 0,0432 \\
\hline $\mathrm{N}_{2}$ & 0,0118 & 0,0186 \\
\hline
\end{tabular}

A câmara de combustão estudada foi dividida em 6 partes para a simulação no CFX, valor referente ao número de injetores presentes na mesma, conforme estudos de Gosselin et al (2000), como também de Rizk e Monglia (1991).
Essadivisãoémuitoimportantedevido a alguns fatos, entre eles: a câmara é formada de iguais setores, favorecendo a análise dos mesmos; possibilidade de fazer uma malha mais refinada com o intuito de melhorar as análises realizadas; menor comprometimento da memória computacional e menor tempo de processamento dos resultados.

O setor estudado da câmara de combustão da microturbina da Solar Turbines, é mostrada na Figura 8. A Figura 8 se refere à geometria estudada no Ansys CFX versão 11 e gerada pelo CFX build versão 5.6. É importante lembrar que o bico injetor, presente na câmara estudada, é um bico alternativo, já que o objetivo foi estudar o escoamento no interior da câmara, sendo que, na câmara de combustão da microturbina da Solar, o bico injetor é mais complexo, $\mathrm{O}$ bico injetor, como também, os orifícios primários e de diluição têm importância significativa para o processo de combustão, de forma que essas análises serão realizadas no decorrer do trabalho.

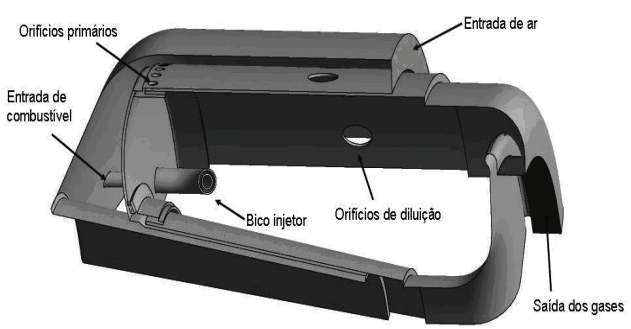

Figura 8. Geometria do setor da câmara de combustão da Solar Turbines

\section{Condições de Projeto}

As condições de projeto foram obtidas através do software GateCycle e do Gaseq.

Os valores dos parâmetros de projeto obtidos pelos programas citados são apresentados na Tabela 2. Para o cálculo da região de injeção de ar primário e de combustível da câmara de combustão e para as simulações foi utilizada uma perda de carga de $2 \%$, sendo a pressão na entrada da câmara de combustão igual a 4 bar.

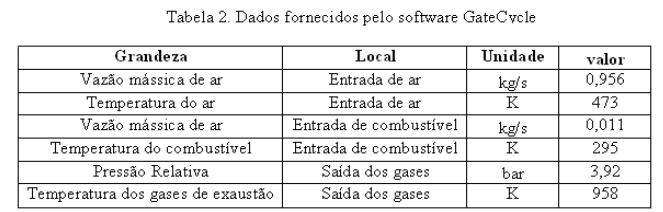

Inicialmente, são definidas as regiões a serem estudadas, de acordo com os dados de entrada coletados. Por exemplo, devese ter uma região definida para a entrada de ar, entrada de combustível e saída dos gases provenientes da combustão. Outra superfície a ser definida é a superfície caracterizada como periódica, ou seja, a superfície de ligação 
entre o setor estudado e o seguinte, e assim sucessivamente até completar toda a câmara. A Figura 9 mostra a definição das superfícies caracterizadas como periódicas, bem como as entradas de ar e combustível e a saída dos gases. A definição das regiões é realizada de acordo com os interesses de cada estudo específico.

Poder-se-ia ter uma geometria na qual uma superfície simétrica seria mais representativa, por exemplo, uma câmara com apenas dois bicos injetores, simétricas relativamente ao eixo $\mathrm{z}$, o que permitiria a utilização de uma superfície simétrica, no lugar de uma superfície periódica.
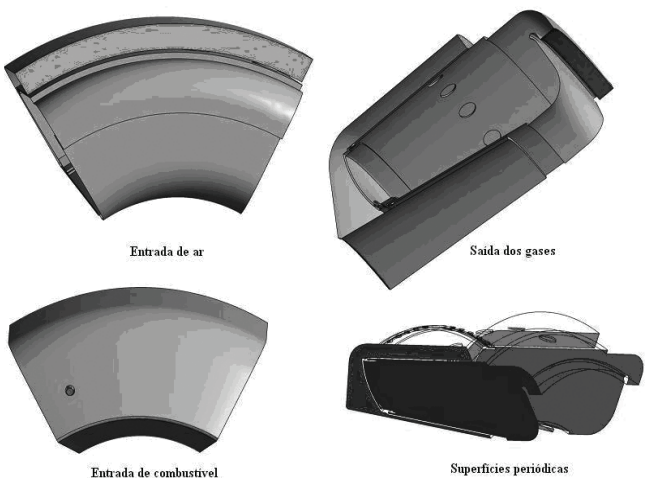

Figura 9. Definição das superficies estudadas conforme entrada de dados

\section{ANÁLISE DOS RESULTADOS}

As simulações deste trabalho foram realizadas num cluster de 40 cores, distribuídos em 5 computadores, com 8 núcleos Intel Xeon Quad-core5420 de 2,5 GHz/12MB, com 16-GB RAM. Devido à complexidade do processo de combustão e da geometria em questão, o tempo de processamento da simulação é relativamente longo. O tempo aproximado para 1000 iterações é de 9 horas. Foram realizadas 1600 iterações, com tempo computacional de aproximadamente 16 horas, utilizando toda a capacidade do cluster.

Para a análise dos resultados foram criados planos, Figura 10, sobre os quais foram gerados os perfis de velocidade e temperatura. Pode-se verificar que o comportamento dos perfis de qualquer parâmetro analisado varia de acordo com o plano em estudo.

Inicialmente, será realizada a análise aerodinâmica, para a verificação da distribuição do ar no interior da câmara de combustão. Para isso, a simulação foi efetuada utilizando ar, também na entrada de combustível. Essa etapa é importante, pois através da análise dos vetores velocidade pode-se verificar a localização da chama, as possibilidades de ancoragem desta chama, como também prever o resfriamento das paredes da câmara de combustão, necessário à integridade do material utilizado para a construção da mesma.

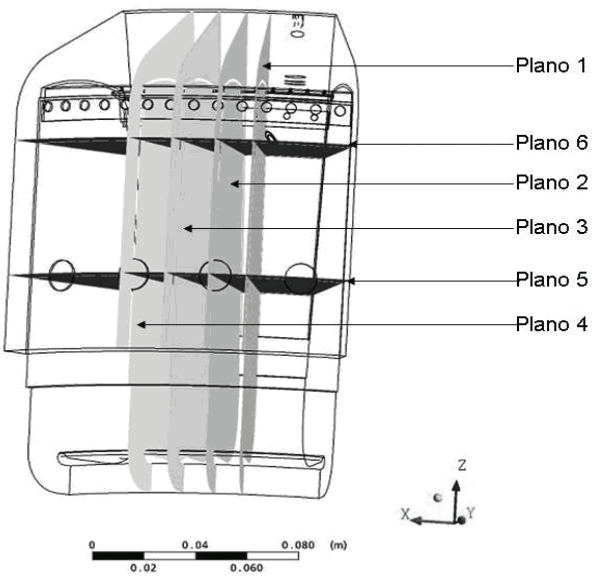

Figura 10. Identificação dos planos estudados (setor unitário)

A Figura 11 mostra os vetores e valores da velocidade ao longo dos planos longitudinais 1 e 2 . No plano 1, pode-se verificar a maior velocidade próxima do bico injetor e a zona de recirculação gerada entre o bico injetor e os orifícios de diluição, fazendo com que a chama tenha a tendência de se ancorar antes dos orifícios de diluição. Este fato é importante, devido à distância que os gases produtos da combustão ainda têm para percorrer até chegar à saída do combustor, proporcionando a dissociação dos poluentes formados no processo de combustão e também fazendo que se tenha uma maior uniformidade da temperatura na entrada da turbina.

Nos planos 1 e 2, também podem ser verificados a maior velocidade próxima das paredes superior e inferior do tubo de chama, na região onde ocorre a chama, fazendo que a chama seja ancorada, não se aproximando nas partes metálicas, mantendo sua integridade.

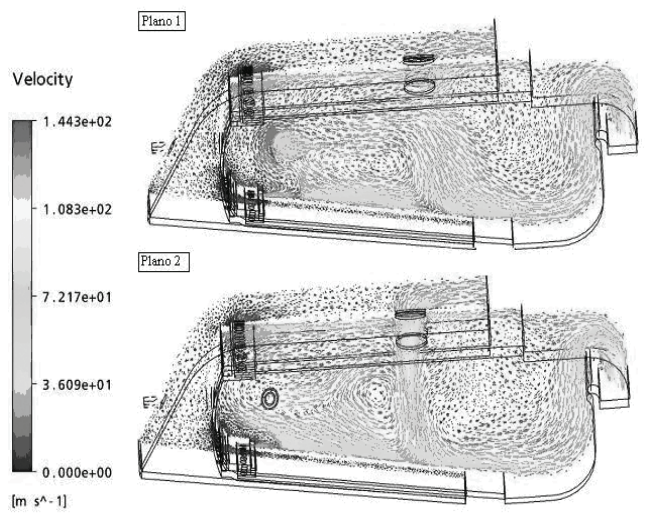

Figura 11 Vetores velocidade ao longo dos planos longitudinais 1 e 2 .

Da mesma forma que na Figura 11, nos planos 3 e 4, mostrados na Figura 6.3, pode ser confirmada a tendência da chama se ancorar entre o bico injetor e os orifícios de diluição, principalmente, no plano 4, que é o plano que passa no centro do orifício de diluição. 


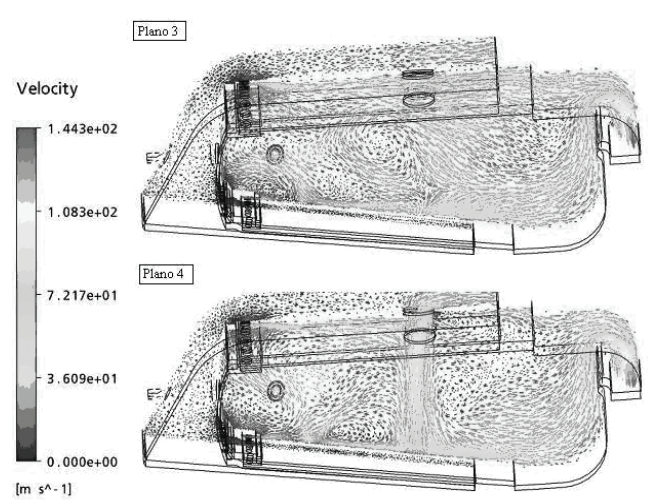

Figura 12 Vetores velocidade ao longo dos planos longitudinais 3 e 4

Comparando os resultados presentes nos planos 1, 2, 3 e 4 pode-se observar a variação dos perfis de velocidade de um plano pra outro, porém em todos os planos se verifica a mesma tendência de localização da chama na região citada na análise de todos os planos.

Com a análise do campo de velocidade, mostrada nos planos 5 e 6 , Figura 13 , pode-se ver a intensificação dos vetores velocidade, de um outro ângulo, sendo que a intensidades desses jatos em todos os orifícios de diluição são muito próximas. Outro ponto a ser observado é a direção da recirculação do ar proveniente do bico injetor, presente no plano 5.

velocity

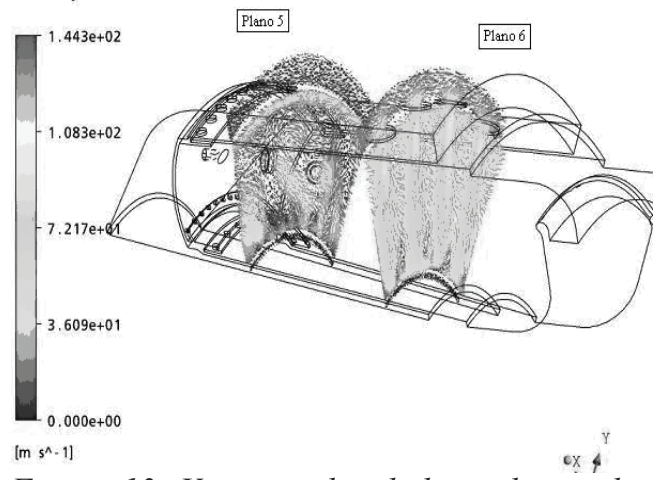

Figura 13. Vetores velocidade ao longo dos planos transversais 5 e 6 .

A análise de vários planos é importante, pois se consegue ter uma visão mais exata do que acontece no interior da câmara, principalmente, na região de maior interesse que, neste caso, é a zona primária e de diluição.

A correta localização da chama e da recirculação na zona de diluição permite uma melhor homogeneização dos gases, produtos da combustão com o ar proveniente do compressor. Esta homogeneização permite uniformizar a temperatura dos gases na saída do combustor e reduzir a temperatura do tubo de chama em toda sua extensão. Além disso, contribui para minimizar o gradiente de temperatura no material do tubo de chama que é o maior causador da fadigas térmicas.
A correta distribuição dos jatos também é importante, pois, eles são responsáveis pela perda de pressão na câmara de combustão.

Através das linhas de correntes, Figura 14, pode-se acompanhar o percurso do fluido, em toda a extensão do setor estudado, sendo possível identificar algum problema que possa existir neste trajeto. Onde as linhas de corrente se aproximam, a velocidade é maior e, onde elas se afastam, a velocidade é menor, portanto, junto às paredes inferiores, nos orifícios e na saída da câmara, têm-se as maiores velocidades.

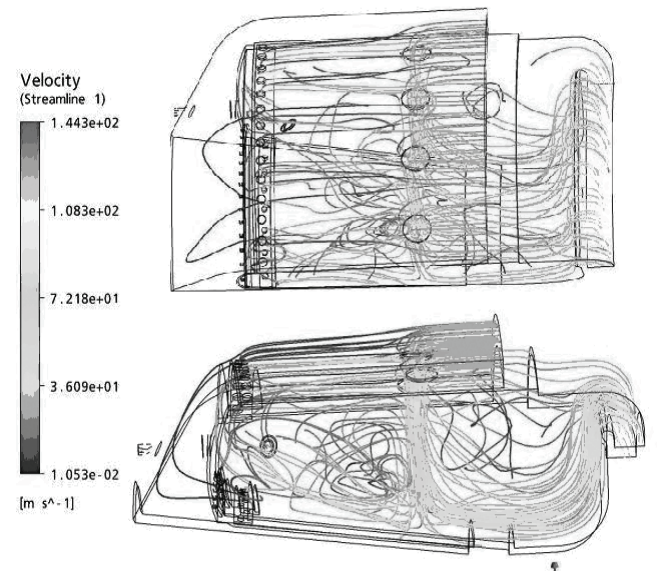

Figura 14. Acompanhamento do escoamento de ar a partir de sua entrada

Várias análises podem ser realizadas utilizando o escoamento do fluido no interior da câmara, como por exemplo, capacidade de deslocamento, intensidade de deslocamento do fluido, variação da velocidade do escoamento próximo a regiões de interesse (bico injetor, orifícios primários ou de diluição).

Através do acompanhamento do fluido, partindo da entrada de ar advinda do compressor, também pode ser verificada a capacidade de resfriamento das partes metálicas por uma camada que forma um filme, impedindo que os gases provenientes da combustão se choquem com as paredes. Esse recurso, presente no CFX, permite controlar o número de linhas que serão traçadas no interior da câmara, sendo que a escolha é feita de acordo com a condição de visualização de todo o escoamento.

Na Figura 15, a mesma análise foi efetuada, porém agora, acompanhando o percurso do ar partindo do bico injetor. Pode-se verificar a maior concentração de combustível na região onde ocorrerá a chama, e uma maior dispersão após os orifícios de diluição. Isso indica que a maior parte do combustível será queimada na região adequada e supõese que os poluentes formados na região da combustão tenham espaço e tempo suficientes para a dissociação, até a saída da câmara de combustão. 


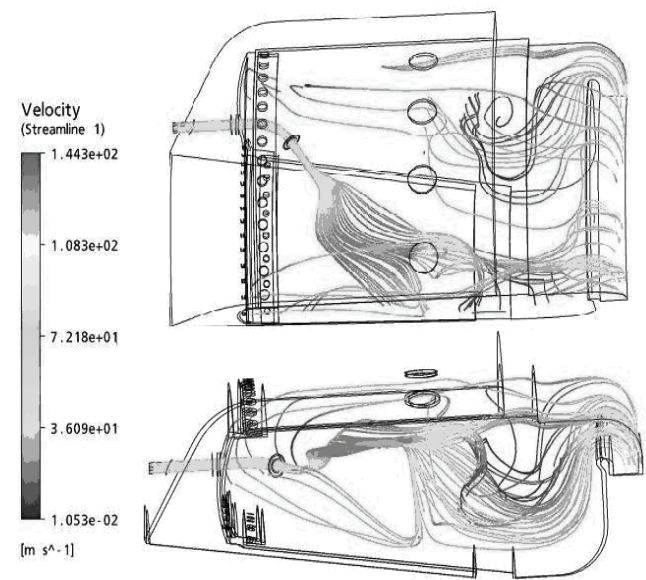

Figura 15. Acompanhamento do escoamento de ar a partir da entrada de combustivel

Até aqui foi analisado apenas o escoamento do ar dentro da câmara de combustão sem considerar a combustão. A partir desse ponto, a análise será realizada incluindo a combustão, o que muda o escoamento dos gases no interior da câmara, pois, as altas temperaturas alteram a massa específica dos mesmos.

A análise dos perfis de temperatura é de extrema importância para o projeto, pois a temperatura está diretamente ligada à eficiência da turbina a gás, assim como, à emissão de poluentes. Como já foi citado anteriormente, é necessária a análise de vários planos dentro do domínio estudado para se ter uma visão geral do que acontece com o fenômeno da combustão.

$\mathrm{Na}$ Figura 16, foram traçados os perfis de temperatura ao longo dos planos longitudinais 1 e 2 , mais próximos do bico injetor de combustível. Conforme pode ser visto nos planos da Figura 16, a chama tem um comportamento não uniforme na zona primária até se aproximar dos orifícios de diluição. Através desses planos, pode-se confirmar a tendência da chama se ancorar antes dos orifícios de diluição, devido às recirculações criadas pelos mesmos, pelos orifícios primários e com a inclinação do bico injetor, como também pode-se verificar que, devido às recirculações, é criado um filme de resfriamento próximo às paredes superior e inferior do tubo de chama.

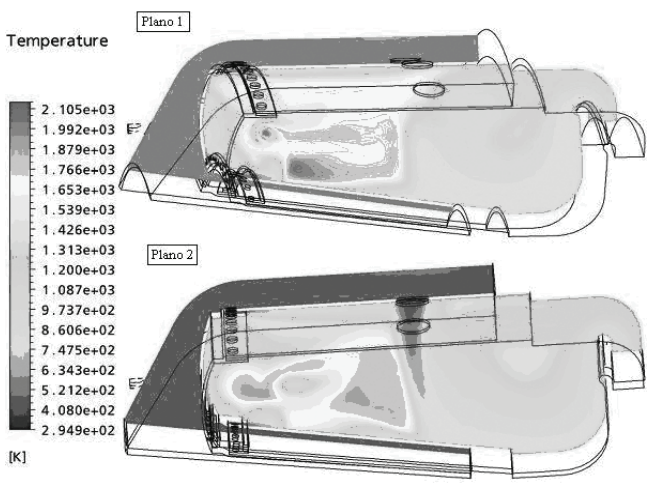

Figura 16. Perfis de temperatura ao longo dos planos longitudinais 1 e 2
$\mathrm{Na}$ Figura 17, são mostrados os perfis de temperaturas ao longo dos planos 3 e 4. Pode-se verificar um comportamento bem diferente dos perfis dos planos 1 e 2 . Nos planos 3 e 4, verifica-se uma maior concentração de temperaturas elevadas na zona primária, confirmando a não uniformidade da chama. Também pode ser verificada uma diminuição na extensão do filme de resfriamento próximo a parede do tubo de chama, sendo a chama nestes planos mais dispersas. A importância da análise de vários plano do mesmo domínio fica novamente evidenciada.

Outro dado a ser verificado é a temperatura de pico da chama igual a $2105 \mathrm{~K}$.

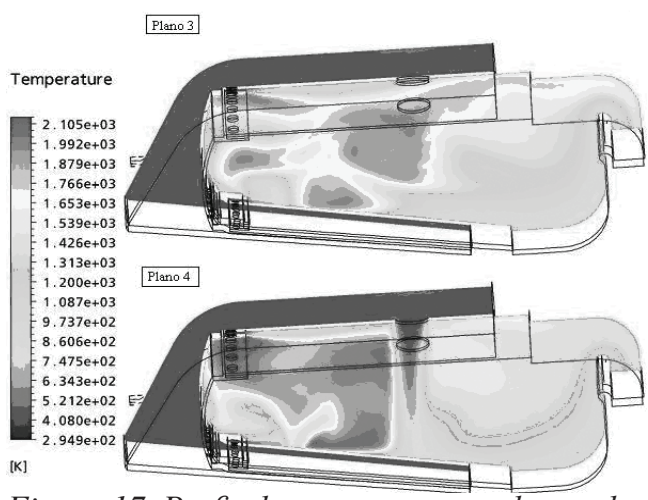

Figura 17. Perfis de temperatura ao longo dos planos longitudinais 3 e 4

\section{CONCLUSÕES}

Com a análise térmica e aerodinâmica da câmara de combustão anular da Solar Turbines, através da Dinâmica de Fluido Computacional, em regime permanente e carga nominal, utilizando gás natural como combustível, pode-se realizar algumas análises da chama como também dos parâmetros da câmara de combustão.

Este estudo permitiu concluir que:

- O modelo de turbulência SST foi adequado para a análise da câmara de combustão em estudo, sendo a mesma de geometria complexa, com vários orifícios e reentrâncias;

- O modelo de combustão Flamelet Model, pareceu ser adequado para a chama produzida na câmara de combustão estudada, porém, deve ser feita uma comparação com outros modelos, como também fazer a validação do modelo utilizado;

- A análise conjunta dos perfis de temperatura e de velocidade é importante para não ser realizada uma análise errônea do fenômeno físico;

- O estudo do comportamento da chama é de suma importância em projetos de turbinas a gás, visto que está diretamente ligada a eficiência e emissão de poluentes;

- Uma metodologia é muito importante para projeto de câmaras de combustão de turbinas a 
gás, do ponto de vista estrutural como também de emissões, utilizando a Dinâmica de Fluido Computacional, visto que, não há na literatura material suficiente para este tipo de análise;

- Pode-se verificar também que a Dinâmica de Fluidos Computacional é uma ferramenta promissora no estudo de câmaras de combustão, devido à sua satisfatória precisão, quando comparado os resultados simulados e os experimentais.

\section{REFERÊNCIAS BIBLIOGRÁFICAS}

COZZI F. e COGHE A. (2006), "Behavior of Hydrogen-Enriched Non-Premixed Swirled Natural Gas Turbines", International Journal of Hydrogen Energy, Volume 3, Issue 6, pp. 669-677.

DARBYSHIRE O. R., EVANS A., WILSON C. W., BECK S. B. M., (2006), "CFDBased Analysis of Burner Fuel Air Mixing Over Range of Air Inlet and Fuel Pre-heat Temperatures for Siemens V94.3A Gas", Proceeding of ASME Turbo Expo, Power and Land, Sea and Air, May 8-13, GT2006-90944, Barcelona, Spain.

ILBAS M.,CRAYFORD A.P., YILMAZ İ. , BOWEN P.J. e SYRED N. (2006), "LaminarBurning Velocities of Hydrogen-Air and Hydrogen-Methane-Air Mixtures: an Experimental Study", International Journal of Hydrogen Energy.

KUO K.K., (1986), "Principles of Combustion", John Wiley \& Sons Edition, New York, EUA.

LAI M. K., (1997), “CFD Analysis of liquid Spray Combustion in a Gas Turbine Combustor", ASME, GT1997-309.

LEFEBVRE A. H. (1983), "Gas Turbine Combustion”, $1^{\text {a }}$ Edition, Mc-GrawHill Book Company, New York, USA.

LORA E. E. S., NASCIMENTO M.A.R, (2004), "Geração Termelétrica, Planejamento, Projeto e Operação", Editora Interciência.

RIZK N. K. e MONGLIA H. C. (1991), "Three dimensional Analysis of Gas Turbine Combustor", Jounal of Propulsion and Power, Vol. $7, \mathrm{~N}^{\circ} 1$

SADIKI A., MANESHKARIMI M.R., CHRIGUI M., JANICKA J., (2004), “CFDAnalysis of Conjugate Effects of Turbulence and Swirl Intensity on Spray Combustion in S Single Gas Turbine Combustor", Proceeding of ASME Turbo Expo, Power for Land, Sea and Air, June 14-17, GT2004-53313, Vienna, Austria.
TECHNICAL MANUAL OVERHAUL (1992), "Titan Gas Turbine T-62T-32 Engine", Division of International Harwester Company, San Diego, CA, USA.

TURREL M. D., STOPFORD P.J., SYED, K. J., BUCHANAN E., 2004, “CFD Simulation of the Flow Within and Downstream of a High-Swirl Lean Premixed Gas Turbine Combustor", Proceeding of ASME Turbo Expo, Power for Land, Sea and Air, June 1417, GT2004-53112, Vienna, Austria.

Endereço para Correspondência:

Lucilene de Oliveira Rodrigues

lucilener@unifei.edu.br

Prof. Dr. Marco Antonio Rosa do Nascimento

Centro Universitário de Volta Redonda

Campus Três Poços

Av. Paulo Erlei Alves Abrantes, no 1325 ,

Três Poços - Volta Redonda / RJ

CEP: 27240-560 